\title{
Understanding the Effects of Deep Space Radiation on Nervous System: The Role of Genetically Tractable Experimental Models
}

\author{
Giada Onorato ${ }^{1,2,3,4}$, Elia Di Schiavi ${ }^{1 *}$ and Ferdinando Di Cunto ${ }^{2,3 *}$ \\ ${ }^{1}$ Institute of Biosciences and Bioresources (IBBR), Consiglio Nazionale delle Ricerche (CNR), Naples, Italy, ${ }^{2}$ Department of \\ Neuroscience "Rita Levi Montalcini", University of Torino, Turin, Italy, ${ }^{3}$ Neuroscience Institute "Cavalieri Ottolenghi", \\ Orbassano, Italy, ${ }^{4}$ Dipartimento di Scienze e Tecnologie Ambientali, Biologiche e Farmaceutiche dell'Università della \\ Campania "Luigi Vanvitelli", Caserta, Italy
}

\section{OPEN ACCESS}

Edited by:

Yolanda Prezado,

INSERM U1021 Signalisation normale et pathologique de l'embryon aux thérapies innovantes des cancers, France

Reviewed by:

Eliedonna Cacao, University of Nevada, Las Vegas, United States

Catherine M. Davis, Johns Hopkins Medicine, United States

*Correspondence: Elia Di Schiav elia.dischiavi@ibbr.cnr.it

Ferdinando Di Cunto ferdinando.dicunto@unito.it

Specialty section: This article was submitted to Medical Physics and Imaging,

a section of the journal Frontiers in Physics

Received: 27 May 2020 Accepted: 28 July 2020 Published: 07 October 2020

Citation:

Onorato G, Di Schiavi E and D Cunto $F$ (2020) Understanding the Effects of Deep Space Radiation on

Nervous System: The Role of Genetically Tractable Experimental Models. Front. Phys. 8:362.

doi: 10.3389/fphy.2020.00362
Space agencies are working to establish a permanent human presence on the moon and to reach Mars within the next few decades. In these missions, astronaut crew members will be exposed to moderate doses of the highly energetic particles that compose galactic cosmic rays (GCR). GCR consist of alpha particles, protons, and high atomic number ions, stripped of their electrons (HZE), which are relatively rare, but are also highly ionizing. HZE are particularly damaging to biological tissues, because they can penetrate to much deeper layers of shielding materials than gamma rays and $\mathrm{x}$-rays and produce within tissues long ionization tracks, with strongly clustered damage to information molecules. The consequences of such damage to central nervous system health is a major concern. A strong development of new knowledge and models, which may help to predict the risk of individual astronauts, is an absolute requirement in this field. Genetically tractable animal models offer unique opportunities to directly investigate the genetic and molecular events that may affect the biological response to GCR and related radiation.

Keywords: space medicine, radiation, HZE, animal models, C. elegans, neurodegeneration, genetic predisposition

\section{INTRODUCTION}

Compared to the terrestrial surface, space represents a hostile environment, characterized by the combination of microgravity, and a peculiar radiative environment, which could lead to severe health issues for astronaut crews engaged in long-term missions. Among these factors, exposure to radiation dominated by particle shots and GCR of extremely high energy is of special concern $[1,2]$. Efficient shielding of such radiation is very difficult, considering the mass constraints which spaceships need to respect. Therefore, it has been noted that "lack of knowledge about the biological effects of, and responses to, space radiation is the single most important factor limiting the prediction of radiation risk associated with human space exploration" [3, 4]. The observations from the ExoMars Trace Gas Orbiter indicate that a 6-month mission to Mars would imply a radiation dose equal to $60 \%$ of the limit which is commonly recommended for the full career of an astronaut [5]. Without major technological leaps in shielding strategies [6], intrinsic or induced biological resilience to space radiation chronic exposure will probably be among the crucial factors to decide about risk acceptability. Individual sensitivity to acute or chronic exposure to radiation is dependent on genetic background [7]. Following recent developments in sequencing technologies, determination of individual genomes and acquisition of multi-omic 
information on individuals' biological samples has become a relatively low-cost routine. In theory, these resources could allow for the screening of many crew candidates, to identify those possessing particularly sensitive or resistant biological backgrounds. However, our knowledge of the genetic and biological traits associated with sensitivity to space radiation is still very limited [7]. NASA has underscored four risks that may imply important health concerns for astronauts: acute radiation syndrome, carcinogenesis, degenerative tissue alterations, and central nervous system (CNS) loss of performance [3]. Among them, the latter is particularly difficult to understand and predict. Nevertheless, recent reports have started to shed some light on this issue $[8,9]$.

In this review, we will briefly summarize the peculiar features of space radiation and the problems posed by its simulation. We will then highlight established and more recent studies on the impact of ionizing radiations and/or space conditions on CNS structure and function, in humans and experimental models. In particular, we will try to summarize the experiments that, in our opinion, are more informative with regard to functional CNS changes that may derive from the exposure of mammalian brain to mission-relevant doses of HZE particles. For a deeper perspective on these topics, the reader is referred to more extensive surveys [10-12]. Afterwards, we will review the studies on genetic factors affecting the general sensitivity to radiation. Finally, we will highlight the experimental models that could provide fundamental insight about genetic and biological factors influencing the response of mature neural networks to space radiation, with particular regard to C. elegans.

\section{SPACE AND SPACE-RELEVANT RADIATION}

The 2006 report by the National Council on Radiation Protection and Measurements (NCRP), concerning space missions beyond low-earth orbit (LEO) [13], underscored that "current space radiation guidelines pertain only to missions in LEO and are not considered relevant for missions beyond LEO. The acceptable levels of risk for space exploration beyond LEO have not been defined at this time and need to be dealt with before sending manned missions to colonize the moon or to deep space, such as a mission to Mars" [13]. Space environment beyond LEO is characterized by a flux of ionizing radiation mostly composed of protons and heavier nuclei stripped of their orbital electrons, but also include a minority (2\%) of electrons and positrons. Manned missions beyond LEO will face the challenge of radiation from three different sources: solar particle events (SPE), galactic cosmic radiation (GCR) and intra-vehicular secondary radiation.

SPE occur when protons emitted by the Sun become accelerated, close to the Sun or in interplanetary space. SPE frequency is correlated with sunspot activity and their occurrences oscillate in phase with the solar cycle. SPE can produce large quantities of protons with energies $>30 \mathrm{MeV}$, at fluences in excess of 109 protons $/ \mathrm{cm}^{2}$ [8]. On missions outside of LEO, SPE dose inside a spaceship can be as high as 100 $\mathrm{mGy} / \mathrm{h}$, but can reach peaks of $500 \mathrm{mGy} / \mathrm{h}$ during extravehicular activity [14]. Due to the high flux and relatively low energy, SPE radiation is absorbed by the most superficial tissues. Skin lesions, hematological, and immunological dysfunctions are therefore the main consequences. For the same reason, shielding is an effective counter-measure. Therefore, although they may certainly contribute to cancer risk and tissues degeneration, SPE are not expected to cause major direct alterations of CNS function.

GCR is composed of nuclei accelerated to relativistic speeds, originating from outside our solar system (Figure 1). Electrons and positrons are of minor concern, because they are stopped by modest shielding. GCR nuclei span a wide range of energy and linear energy transfer (LET). The major components consist of hydrogen $(87 \%)$, and helium (12\%) nuclei, with the remaining $1-2 \%$ of particles are comprised from $Z=3(\mathrm{Li})$ to $Z=28$ (Ni) [15]. High-Z and energy particles (HZE), such as iron $(Z=$ 26), are particularly challenging, because every particle can cause damage to cellular DNA which is difficult to repair [16] and no reasonable thickness of shielding material can safely stop them [6]. GCR particle energy allows them to penetrate very deeply into biological tissues, as well as other organic and inorganic materials. In particular, HZE nuclei are an outstanding threat to body cells, which may strongly contribute to the cumulative equivalent dose absorbed by astronauts beyond LEO. Shielding is only partially effective to reduce the doses experienced inside a spacecraft $[2,6]$, but increasing shields' thickness leads to the production of high levels of secondary radiation, which can be absorbed even more easily by biological tissues [17]. HZE nuclei may strongly contribute to the carcinogenic risk to which crew members are exposed. Indeed, even at relatively low energy, iron ions are shown to be potent inducers of ovarian tumors formation in rodents [18]. Due to their high penetration power, GCR can efficiently reach CNS cells and pose a major risk to CNS function. However, the effects of chronic exposure to this kind of radiation on nervous system function and CNS cells' survival, as well as the factors that may protect from such damage, are still not well-understood.

The interaction of energetic protons and HZE nuclei with spacecraft structures can produce an additional intravehicular radiation hazard. Secondary radiation includes beta particles, $\mathrm{x}$ rays, gamma rays, neutrons, protons, alpha particles, and heavycharged particles, mostly produced in nuclear fission reactions. Secondary radiation has lower particle energy, but can be even more disruptive to tissues than incident radiation particles, delivering a significant fraction of the total dose absorbed during missions. Although the capability of such radiation to deeply penetrate into biological tissues is lower than incident GCR, it can be sufficiently high enough to deliver a significant dose to CNS cells.

On this basis, it should be evident that crew members of missions aimed at the moon, asteroids or Mars will be exposed to a very complex radiation environment, which can significantly change qualitatively and quantitatively in space and time. Predicting the equivalent dose associated to the different conditions is an extremely difficult task [4]. Among the major challenges, it is very problematic to understand the consequences of chronic exposure to low doses of extremely energetic GCR, 


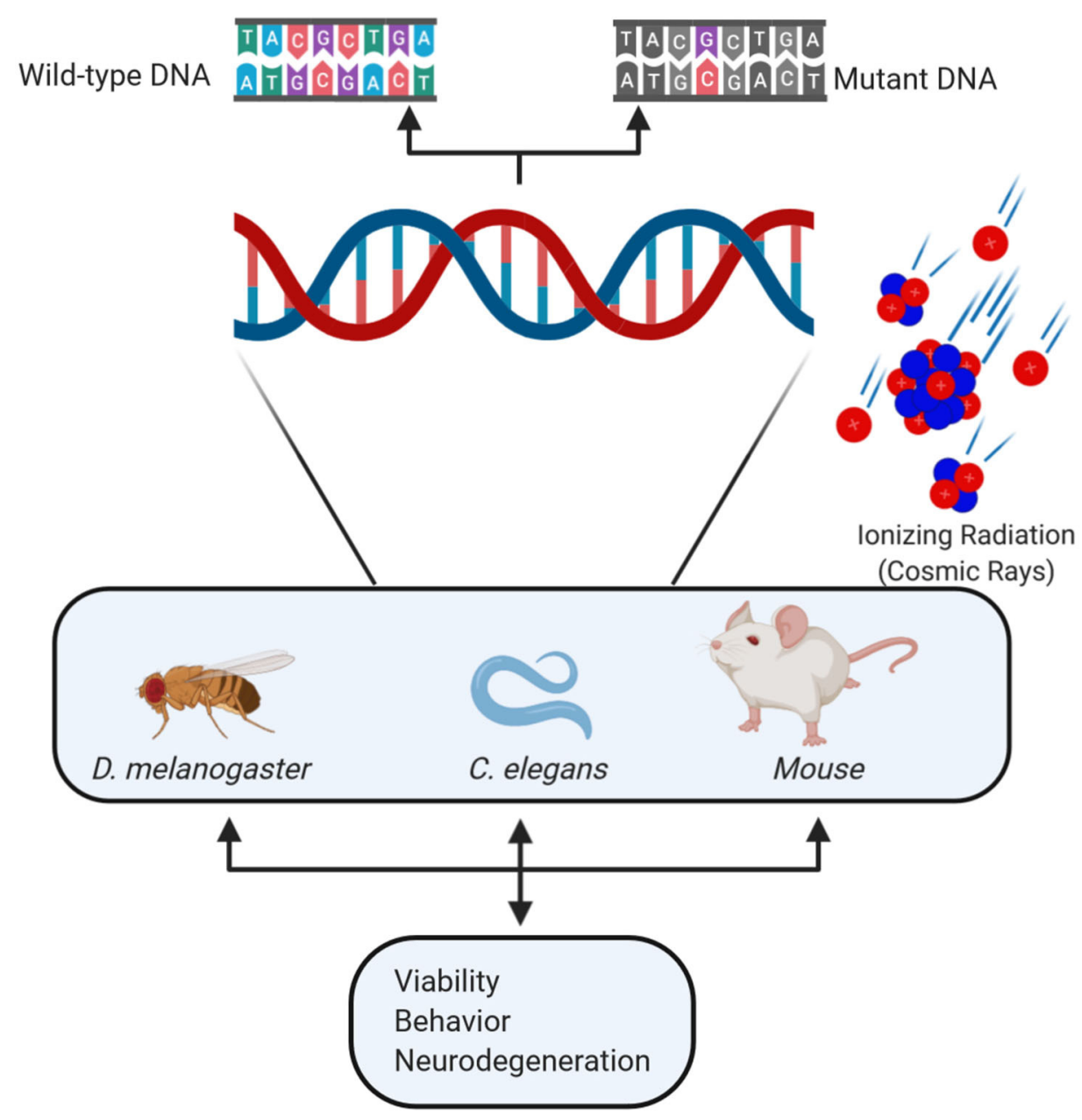

Created in BioRender.com bio

FIGURE 1 | Schematic representation of the main components of space radiation and of the principal model organisms used to study their effects on differentiated neural tissues.

combined with the secondary radiation. High LET radiation is very damaging to informational biomolecules, especially DNA. Different gene expression programs and different sets of protein phosphorylation events are produced when cells and tissues are exposed to low vs. high doses of conventional radiations [1]. So far, the strongest direct evidence about genotoxicity of GCR in humans is the cytogenetic comparison of cells obtained from Gemini vs. Apollo astronauts, showing a doubling in chromosome breaks [19]. Many studies of high-LET radiation effects have been so far performed on animal models, especially rodents. However, these studies suffer major limitations [4]. They have been limited to a maximal particle energy of $1 \mathrm{GeV} / \mathrm{n}$, thus excluding particles possessing the highest energy, which are estimated to contribute to approximately half of the dose [4]. Moreover, they were conducted using mono-energetic beams and acute, single-ion exposures, instead of complex energy spectra with diverse ion composition [4]. GCR simulation facilities, such as the NASA Space Radiation Laboratory (NSRL) in the US and the Facility for Antiproton Research (FAIR) in Europe are constantly improving on this limitation, by increasing particles energy and developing protocols for sequential exposure to different ion beams. However, sequential beam exposures appear to be not completely adequate in mimicking simultaneous exposure to a wide spectrum of particles and energies, since it has been shown that the order of delivered particles can significantly modify the biological effects [20]. Moreover, the dose-rate administered through accelerators will probably remain higher than low fluency radiation occurring during real missions [21, 22].

Non-linearity of biological effects of GCR could also depend on adaptation mechanisms. After missions in ISS, astronauts' lymphocytes showed complex chromosomal rearrangements, 
involving more than three chromosomes [23], which decreased but did not reach control levels even after many years. Nevertheless, controls performed after a second mission did not show a proportional increase of chromosomal aberrations, suggesting that an adaptive response may take place [23]. On this basis, it is evident that direct measurement of the biological effectiveness of space radiation, using adequate living experimental models, should be considered an inevitable milestone of space exploration.

\section{EFFECTS OF SPACE-RELEVANT RADIATION ON MAMMALIAN CNS}

In theory, human exploration of space may imply acute and late radiation risks to the $\mathrm{CNS}[8,24]$. Acute $\mathrm{CNS}$ risks include functional changes that may compromise astronauts' performance during the mission, such as altered cognition and mood, as well as abnormal motor coordination. Acute effects could derive from exposure to SPE, that can reach $0.5 \mathrm{~Gy}$ in the case of concomitant extra-vehicular activity (EVA) or permanent spaces not properly shielded [25, 26]. However, the energies of SPE are usually limited to the 10$100 \mathrm{MeV}$ range, allowing efficient shielding and implying that most energy is delivered to superficial tissues, especially skin. In addition, it must be considered that doses of IR up to $2 \mathrm{~Gy}$ are currently used in brain radiotherapy, with limited immediate side effects. The concern about CNS functions is much more related to the cumulative medium-term and longterm alterations, produced by prolonged exposure to a lowfluency $(<20 \mathrm{mGy} / \mathrm{h})$ of protons, HZE nuclei and neutrons, deriving from SPE flares, GCR, and their combinations in time. Neural alterations induced by space flight may impact on learning and memory, motor function, orientation, bio-rhythms regulation, and neuro-psychological changes, such as emotional control and risk evaluation $[8,27]$. The latest possible effects are neurodegenerative disorders, such as Alzheimer's and Parkinson's diseases ( $\mathrm{AD}$ and $\mathrm{PD}$, respectively).

Direct evidence of CNS effects produced by moderate radiation doses of $(\leq 2 \mathrm{~Gy})$ derive from studies performed on atomic bombs survivors and Chernobyl accident victims, who showed memory and cognitive impairments, as well as psychiatric disorders and altered electroencephalographic (EEG) patterns [28, 29]. These studies are limited by uncertain dosimetry, short exposure times, and radiation type. Additional evidence has been obtained from radiotherapy patients, who often show chronic fatigue, depression, and other behavioral changes [30, 31]. However, administered doses are too high and inhomogeneous to be fully relevant for the space environment. This is particularly true for the few "opportunistic" studies conducted on patients treated with protons and other charged particle beams for different types of intracranial tumors [32-34] and cerebrovascular disorders $[35,36]$. Interestingly, many of these studies have shown that cognitive impairment is not evident in the first year but becomes detectable during long-term followup. Importantly, brain MRI (magnetic resonance imaging) surveys of 11 astronauts, involved in long LEO missions, clearly showed that long-term microgravity can contribute to brain changes caused by radiation exposure [37].

Data from non-human primates, irradiated with relatively high doses in different experiments, mostly confirmed the detrimental effects of radiation on the execution of different behavioral tasks $[8,38]$. Similar conclusions have been obtained with pilot tests performed at much lower doses, which produced changes in food preferences and degradation in test performance [39]. However, a provocative study performed with doses on the order of $1 \mathrm{~Gy}$ suggests that chronic exposure to space-related conditions can enhance some behavioral traits. A group of rhesus monkey males were subjected to 20 to 40 exposures of fast neutrons and gamma rays, achieving cumulative doses of up to 600 cGy [40, 41]. During the first six months of follow-up no alterations were observed. However, behavioral tests performed after 9-10 months were indicative of decreased distractibility in the irradiated animals, with increased performance in attention tests, which persisted at 14,36 , and 78 months.

Analyses of rodent models have provided the most extensive evidence about the potential neurocognitive complications caused by GCR (Table 1), which could affect skills critical for missions, as well as long-term neuro-psychological health $[8,10$, 24]. Low doses (5-20 cGy) of $1 \mathrm{MeV} / \mathrm{n}^{56} \mathrm{Fe}$ particles lead to severe deficits of mean spatial memory performance in rats, three months after exposure [42-44]. Similar effects where obtained by irradiating rats with low doses of ${ }^{48} \mathrm{Ti}$ [65], supporting the notion that LET-dependency of neurocognitive impairment may be relatively independent of cell killing. RBE of HZE particles on memory alteration was extremely high, if considering that $\mathrm{x}$-ray exposure can alter memory in rats only at doses as high as $10 \mathrm{~Gy}$ [66]. Since performance in the attentional set-shifting test was also compromised [44], these experiments indicate that missionrelevant exposure to HZE particles may decrease function in the hippocampus and many other different brain regions, including the prefrontal and cingulate cortex as well as the basal forebrain. Similar effects were obtained in mice, exposed to 5-30 cGy 600 of $\mathrm{MeV} / \mathrm{n}{ }^{48} \mathrm{Ti}$ and ${ }^{16} \mathrm{O}$ [47]. Even though ${ }^{48} \mathrm{Ti}$ was more effective on disrupting recognition memory, significant longlasting alterations in novelty and temporal discrimination tests were induced even by the lowest dose of ${ }^{16} \mathrm{O}$ [47]. Moreover, reduced fear extinction and increased anxiety were detected [47]. Another crucial insight of studies in mice is that the effects of GCR could be strongly influenced by sex and gender. Adult male mice, exposed to simulated GCR (single doses, as high as 50 cGy), showed long term effects like anxiety-related phenotypes, reduced social interaction, and impaired memory [48]. In contrast, female mice of the same age were largely protected from these phenotypes [48].

Interestingly, the studies performed in rodents showed a high inter-individual variability in HZE-induced neurobehavioral deficits. In particular, in the low-range dosage, deficits were particularly pronounced in a subgroup of poor-learner animals [43]. This result strongly suggests the involvement of individual genetic factors, although the specific involved loci were not investigated.

The great sensitivity of CNS to HZE particles is related not only to radiation-induced neuronal cell death, but may derive 
TABLE 1 | Summary table of the principal genes affecting response to space-relevant radiation in the principal experimental models, including the altered behavior and functionality with the indicated radiation exposure.

\begin{tabular}{|c|c|c|c|}
\hline Model organism & Genetic background & Radiation source & Effect \\
\hline \multirow[t]{15}{*}{ Mouse/Rat } & Wild-type & $5-20 c \mathrm{c} y$ of $1 \mathrm{MeV} / \mathrm{n}^{56} \mathrm{Fe}$ & Spatial memory [42-44] \\
\hline & & & Anxiety [45] \\
\hline & & & Depression-like behavior [46] \\
\hline & & $\begin{array}{l}5-30 c G y \text { of } 600 \mathrm{MeV} / \mathrm{n}^{48} \mathrm{Ti} \text { or } \\
{ }^{16} \mathrm{O}\end{array}$ & $\begin{array}{l}\text { Alteration of functions in hippocampus, cingulate cortex, and basal } \\
\text { forebrain [47] }\end{array}$ \\
\hline & & & Disruption of recognition memory [47] \\
\hline & & GCR-like radiations & $\begin{array}{l}\text { Alteration of synapses and spine morphology in behaviorally-relevant } \\
\text { areas }[12,47]\end{array}$ \\
\hline & & & Microglia activation and synapse loss in males [48] \\
\hline & & & Anxiety phenotypes in males [48] \\
\hline & & & Reduced social interactions in males [48] \\
\hline & & & Impaired memory in males [48] \\
\hline & ATM heterozygosity & $1 \mathrm{GeV}^{56} \mathrm{Fe}$ & Unrepaired DNA DSB [49] \\
\hline & & & Neurological sensitivity $[50,51]$ \\
\hline & $\begin{array}{l}\text { Transgenically expressed APP23 } \\
\text { (AD model) }\end{array}$ & $1-4$ Gy of $600 \mathrm{MeV} / \mathrm{n}^{56} \mathrm{Fe}$ & Electrophysiological alterations in males [52] \\
\hline & $\begin{array}{l}\text { Transgenically expressed ApoE3 } \\
\text { (AD model) }\end{array}$ & $2 \mathrm{~Gy}{ }^{56} \mathrm{Fe}$ & Impairment in spatial memory [53] \\
\hline & $\begin{array}{l}\text { Transgenically expressed } \\
\text { APP/PSEN1 (AD model) }\end{array}$ & $0.1-1$ Gy of $150 \mathrm{MeV}$ protons & 4 Amyloid A $\beta$ deposition [54] \\
\hline \multirow[t]{3}{*}{ D. melanogaster } & Wild-type & GCR-like radiations & Alteration of immune response [55] \\
\hline & & & $\begin{array}{l}\text { Deregulation of the expression of genes involved in metabolism and } \\
\text { lifespan regulation [56] } \\
\text { Extension of lifespan [56] }\end{array}$ \\
\hline & & Low-dose- $\gamma$ radiation & Behavioral alterations [57] \\
\hline \multirow[t]{8}{*}{ C. elegans } & Wild-type & GCR-like radiations & 4 Deletion mutations $[58,59]$ \\
\hline & & & Deregulation of neuromuscular and neuronal genes $[58,59]$ \\
\hline & & & Extension of lifespan due to the upregulation of daf-16 [60] \\
\hline & & & DNA DSB and deletion mutations [61] \\
\hline & & & Apoptosis and cell-cycle arrest in germ cells [61] \\
\hline & & & Alteration of fertility and embryos' development [62] \\
\hline & & & Behavioral alterations $[63,64]$ \\
\hline & $\begin{array}{l}\text { Transgenically expressed PolyQ in } \\
\text { muscle cells (Huntington model) }\end{array}$ & & $\downarrow$ Accumulated aggregates [60] \\
\hline
\end{tabular}

from the alteration of different aspects of neuronal function [42]. Irradiation reduced dendritic complexity and spine density and altered the morphology of dendritic spine in behaviorallyrelevant areas [12, 47]. HZE particles were also capable of disrupting synaptic integrity and inducing neuroinflammation, which persisted for more than 6 months after exposure [47]. Microglia activation is mechanistically important in determining the long-term synaptic and memory deficits, because these phenotypes can be prevented by transiently depleting microglia cells, through the administration of a CSFR-1 inhibitor 7 days after irradiation $[67,68]$. Even these phenotypes appear to be sex-dependent, since microglia activation and synapse loss were observed only in males, after exposure to GCR-like radiation [48]. Irradiation produced many different neurophysiological alterations, which have been well-measured in the perirhinal cortex, including changes in both intrinsic and extrinsic neuronal properties [69]. Studies in rodents also showed that the effects of irradiation on CNS transcriptional activity and epigenetic state can be potentiated by simulated microgravity [70].

\section{GENETIC MODIFIERS OF SPACE RADIATION IMPACT ON CNS}

The studies discussed above provide strong evidence that the deep space radiation environment may influence the function and plasticity of neural networks controlling human behavior, within mission time and beyond. An even more challenging problem is to establish whether specific genetic variants or variant combinations would make individuals particularly sensitive or resilient to these hostile conditions. The identification of relatively radiosensitive sub-populations within human communities has important implications for space medicine, because it would be unethical to expose radiosensitive individuals 
to conditions that may produce a severe clinical response. Moreover, the existence of a significantly radiosensitive subpopulation would pose a big challenge to epidemiological studies addressing dose-response relationships, because it would hamper the conceptual assumptions necessary for linear extrapolations from high to low doses [71].

A large body of knowledge is available about genetic factors that may influence human sensitivity to radiations. Not surprisingly, most of the strongest genetic players are involved in some of the pathways that cope with DNA damage. A better understood factor is the status of the ATM gene. The encoded protein belongs to the PI3-kinase family and responds to DNA damage, especially double strand breaks (DSB), by phosphorylating a plethora of proteins playing critical roles in DNA repair, as well as in the control of the cell division cycle [72]. The inactivation of both ATM copies is responsible for the ataxia-telangiectasia (AT) syndrome, which is characterized by extreme radio-sensitivity, cancer predisposition, and cerebellar neurodegeneration. A more relevant question for space medicine is whether individuals heterozygous for ATM mutations, who represent at least $1 \%$ of the US population [73], are more radiosensitive than normal people. Studies performed on small groups of patients, showing severe late consequences of radiotherapy, revealed a disproportionate frequency of ATM heterozygous mutations and also suggested that other genetic factors are involved [71, 74]. The possibility that ATM heterozygosity is an important susceptibility factor to HZE effects was confirmed by studies on cultured human cells [75] and on haplo-insufficient mice [50, 51]. Importantly, the latter studies showed increased neurological sensitivity of ATM heterozygous mice to relatively low doses of $1 \mathrm{GeV}$ ${ }^{56} \mathrm{Fe}$ particles. Besides ATM, a number of other rare recessive disorders are characterized by increased radio-sensitivity [76]. These include Fanconi anemia, Nijmegen breakage syndrome (caused by mutation in NBS1 gene), MRE11 deficiency, and other more rare disorders [76, 77]. All these conditions share a deficiency in coping with the radiation-induced DSB, because of reduced DSB sensing, impaired homologous recombination (HR), or defective non-homologous end-joining (NHEJ). While these diseases are not expected to be present in crew member candidates, it is conceivable that heterozygous inactivation of the same genes could increase the risk of abnormal radiation sensitivity in apparently normal subjects. Besides ATM, modestly increased sensitivity to $\mathrm{x}$-ray has been demonstrated in NBS1 heterozygous mutant cells [78]. It is not known whether HZE particles could unmask an even higher sensitivity in these conditions. The potential consequences on CNS of heterozygous mutations in crucial DSB repair genes are even more obscure. Increased neurodegeneration occurring in homozygous patients is suspected to derive from the accumulation of unrepaired DNA DSB [49]. Indeed, defective DNA repair has also been observed in neurodegenerative disorders associated with aging, which include Alzheimer's disease (AD), Parkinson's disease (PD), amyotrophic lateral sclerosis (ALS) [79-82], and epilepsy [83]. Although most studies linking DNA damage to neurodegeneration are correlative [49], recent evidence obtained on a mouse model of $\mathrm{AD}$-like neurodegeneration indicates that
DSBs accumulate before the onset of neurodegeneration [84], suggesting a causal link.

Genetic susceptibility factors to neurodegenerative disorders may also synergistically interact with space-relevant radiation. Irradiation of APP/PSEN1 transgenic mice with $0.1-1.0 \mathrm{~Gy}$ of $150 \mathrm{MeV}$ protons increased amyloid $\mathrm{A} \beta$ deposition, but did not worsen the functional and biochemical alterations that characterize this AD model [54].

In contrast, APP23 transgenic male mice, irradiated with 1-4 Gy of $600 \mathrm{MeV} / \mathrm{n} \quad{ }^{56} \mathrm{Fe}$, showed accelerated electrophysiological alterations in the hippocampus [52]. Even at much lower doses (10 or $50 \mathrm{cGy}$ ) of $1 \mathrm{GeV} / \mathrm{n}{ }^{56} \mathrm{Fe}$ ions showed genotype-specific changes in neuropathology and behavior of AD-like transgenic mice [85]. Interestingly, even in this case the phenotype showed complex differences between males and females [85]. Transgenic mice expressing the E3 variant of ApoE were more sensitive to impairment in spatial memory induced by $2 \mathrm{~Gy}{ }^{56} \mathrm{Fe}$ irradiation, as compared to mice expressing E2 or E4 variants [53].

Even less information is available about genetic conditions that may increase radio-resistance, especially in the CNS. To this regard, the best understood pathway is the one activated by the p53 tumor suppressor TP53. However, although partial TP53 loss of function may help cells to better survive, it would also increase the risk of cancer [86].

Altogether, these studies strongly support the notion that specific genetic factors may influence the effect of the space radiation environment. However, they also underscore the difficulties that the analysis of genomic data must face, in order to predict the risks of a specific subject. These limits are primarily due to our primitive understanding of the interaction between HZE radiation and genetic susceptibility factors. A second important problem is the likely polygenic nature of the genetic susceptibility, requiring the elaboration of sophisticated polygenic risk scores. It is unlikely that the latter could be developed using standard genome wide association studies, when considering the extremely small subjects' number that direct epidemiologic studies can reasonably include. A possible way around this problem could be offered by astronaut-specific induced pluripotent stem cells (iPSC). Thanks to the present development of stem cell technologies, iPSC can be differentiated in most of the relevant cell types, including CNS cells. The direct determination of radio-sensitivity of astronaut-specific cells could provide accurate predictive biomarkers, regardless of the underlying genetic background [87]. Moreover, innovative polygenic risk scores could be derived by better dissecting the biological details of the interaction between HZE radiation and genetically tractable animal models, which are relatively easy to study in space-like and actual deep space conditions.

\section{ROLE OF GENETICALLY TRACTABLE MODELS IN THE STUDY OF BIOLOGICAL EFFECTS OF SPACE RADIATION}

The use of relatively simple and fully tractable experimental models is pivotal to investigate the impact of deep space 
conditions on different aspects of multicellular organisms' biology, including genome stability, behavior, and neuronal survival. In this respect, a simpler vertebrate alternative is offered by small fish models, such as Zebrafish and Medaka [88, 89]. However, the most flexible alternative to mammalian models for studying the impact of space environment on adult neural cells is offered by the invertebrates Drosophila melanogaster and Caenorhabditis elegans (Figure 1 and Table 1). Indeed, they have a very small size ( 3 and $1 \mathrm{~mm}$ long, respectively), a very short life cycle ( 2 and 0.5 weeks, respectively), and life span (90 and 21 days, respectively), as well as a simple anatomy including a nervous system; their entire genome, physiological, and behavioral characteristics are well-understood [90]. Thanks to the availability of thousands of genetically modified strains, it is possible to assess the functional relevance of specific genetic alterations and to test sophisticated genetic hypotheses. Practically, these models can allow for the screening of many gene candidates, to identify those conferring particularly sensitive or resistant biological backgrounds. Being invertebrates, they both raise fewer concerns for experimentation, as compared to vertebrates. However, considering their good genomic and cell biology phylogenetic conservation, they have been and will be fundamental for understanding the molecular mechanisms and physiological processes which characterize more complex organisms, such as humans. Multiple times the Nobel prize has been awarded to researchers working with these two models, thus acknowledging their fundamental contribution to understanding details of the molecular processes underlying many human diseases. In addition, they have been shown to be highly versatile models in studies covering different topics highly relevant to space biology and medicine, which include the genetics and molecular biology of aging, development, muscle physiology, and radiation response.

D. melanogaster has been used in space missions since 2015, during the Fruit Fly Lab-01 (FFL-01), which provided housing for fruit flies under conditions of microgravity and simulated Earth gravity. Experiments revealed that ionizing space radiations can alter innate immune responses [55]. Chronic low-dose$\gamma$ radiation led to behavioral alteration in D. melanogaster, inducing impaired climbing activity and exploratory movement [57]. Low-dose radiation affects the expression of genes involved in D. melanogaster metabolism and lifespan regulation, causing a surprising extension [56]. However, it is still largely unknown how this effect may occur.

Caenorhabditis elegans is a nematode with a defined number of cells (959 somatic cells in the adult), among which 302 are neurons. It has proven to be a useful model organism for investigating molecular and cellular aspects of neuron development and neurodegeneration in numerous human diseases, including PD and other neurodegenerative conditions [91, 92]. Moreover, the degeneration of specific neuronal populations, can be easily analyzed in living animals [93], thanks to their transparency and the expression of fluorescent proteins. The choice of C. elegans is specifically justified by the following elements: a high resistance to extreme conditions (also thanks to a cuticle); the possibility of hibernation (i.e., as dauer larvae, a resistant larval stage) and of freezing; the self-fertilizing hermaphroditism that avoid the need for crossings; a large progeny (300 eggs per each animal); and the possibility to culture them in microfluidic devices [94].

Caenorhabditis elegans has traveled 12 times in space and experiments have been performed in the Space Shuttle and on the ISS. Therefore, much information has been obtained, which will not be discussed here [95]; in relation with the focus of the present review, C. elegans explored space for the first time on STS-42, allowing researchers to demonstrate no alteration in males mating behavior during spaceflight [96]. In the STS-76 mission, a high number of mutations were shown as the direct effect of space radiation and not microgravity. In particular, high-LET charged particles caused deletion mutations $[58,59]$. ICE-First (International C. elegans Experiment-I) was the fifth spaceflight for the nematode, and the first on-board the ISS [97]. Results from the space flight experiment provided information on how radiation and microgravity influences worm development throughout the life cycle and worm muscle physiology, as well as which are the changes in gene expression [97]. Interestingly, relevant spaceflight-induced changes in expression of neuromuscular and neuronal genes have been specifically determined [58, 59]. Moreover, genes involving lifespan extension, such as daf-16, are upregulated after spaceflight, suggesting that space-flight might increase nematodes' survival [60]. These effects seem related to the alteration of neuronal and endocrine signaling involved in "longevity-promoting" processes, similar to those activated by dietary-restriction signaling [60].

A model for Huntington's and related neurodegenerative disorders, transgenically expressing polyQ in muscle cells, accumulates aggregates with aging. This accumulation was suppressed in C. elegans after spaceflight and gene expression analysis showed that aging in $C$. elegans may be slowed through neuronal and endocrine adaptation to space-related stressors [60].

Contrary to the abundant information on genome stability and muscle physiology after spaceflights, less is known of the neuron response, despite C. elegans being selected as an elective model for neurobiology studies [98, 99]. More information has been obtained on Earth, by studying the effects of radiation on the nematode. Ionizing radiation induces several changes in terms of biological and physiological processes [61]. As in mammalian cells, they can induce DNA DSB and deletions, leading to apoptosis and cell-cycle arrest. This occurs especially in the germ cells in which, after irradiation, apoptosis and cell-cycle arrests significantly increase [61]. Adult nematodes tolerate both acute and chronic high-dose irradiation with minor consequences, apart from a reduction of fertility, thus allowing for studying the effects on adult animals. Parental exposure leads to DNA damage in embryos, but the progeny maintains high reproductive capacity, despite a reduction of somatic growth [62]. Interestingly, the cell death pathway activated by ionizing radiation in germ cells is different from the pathway involved in physiological apoptosis [62]. Recently, transcriptome sequencing revealed a series of novel ionizing radiation-response genes [100]. Moreover, radiosensitive (e.g., rad-1 and rad-2) and radioresistant (e.g., $c d c$-25.3) mutants have been identified [101, 
102]. Ionizing irradiations also have effects on learning behavior and the locomotory rate. In particular, radiation affects salt chemotaxis learning behavior, which is an associative learning paradigm $[63,64]$. This phenotype resembles the taste aversion observed in the group of male rhesus monkeys described above [40, 41], or in rodents [45]. Moreover, the altered learning produced by radiation was inhibited in the $g p c-1$ mutant, lacking one gamma subunit of the heterotrimeric G-protein. The effects of radiations on the locomotor behavior have also been studied. The ionizing radiations induced a reduction of the locomotor rate, mediated by a pathway different from the dopaminergic pathway in place for bacterial mechano-sensing [63].

All these results explain how C. elegans offers potential for the design of an innovative biological dosimeter. The frequency and types of mutations generated and maintained in C. elegans have been deeply assessed $[103,104]$. An interesting step forward will be to use $C$. elegans as an accumulating dosimeter for neuronal defects. The possibility of phenotyping neural cells at high resolution, in combination with the genetic tractability of C. elegans could make the nervous system of this small organism an excellent model to assess the consequences of chronic exposure to relatively low doses of space-relevant radiations, although it will be necessary to adapt the dose to its short lifespan and high radio-resistance. Using standard and genetically modified strains and dynamic microscopy, the phenotyping could be done over multiple/daily treatments during life. The following quantities can be measured and correlated with the radiation dose: movement, chemotaxis, and expression of fluorescent markers to monitor neurons morphology. Moreover, thanks to its short life-cycle, the phenotyping could be done in C. elegans over multiple generations in space, as NASA has called for. The combination with sequencing technologies, which have recently been implemented on board the ISS, will allow

\section{REFERENCES}

1. Chancellor JC, Scott GBI, Sutton JP. Space radiation: the number one risk to astronaut health beyond low earth orbit. Life. (2014) 4:491-510. doi: 10.3390/life4030491

2. Durante M. Space radiation protection: destination mars. Life Sci Space Res. (2014) 1:2-9. doi: 10.1016/j.lssr.2014.01.002

3. Council NR. Managing Space Radiation Risk in the New Era of Space Exploration. (2008). Available online at: https://www.nap.edu/catalog/ 12045/managing-space-radiation-risk-in-the-new-era-of-space-exploration (accessed September 21, 2020)

4. Chancellor JC, Blue RS, Cengel KA, Auñón-Chancellor SM, Rubins $\mathrm{KH}$, Katzgraber $\mathrm{HG}$, et al. Limitations in predicting the space radiation health risk for exploration astronauts. NPJ Microgravity. (2018) 4:8. doi: 10.1038/s41526-018-0043-2

5. de Vera JP, Alawi M, Backhaus T, Baqué M, Billi D, Böttger U, et al. Limits of life and the habitability of mars: the ESA space experiment BIOMEX on the ISS. Astrobiology. (2019) 19:145-57. doi: 10.1089/ast.2018.1897

6. Wilson JW, Cucinotta FA, Kim MH, Schimmerling W. Optimized shielding for space radiation protection. Phys Med. (2001) 17 (Suppl. 1):67-71.

7. Rajaraman P, Hauptmann M, Bouffler S, Wojcik A. Human individual radiation sensitivity and prospects for prediction. Ann ICRP. (2018) 47:12641. doi: 10.1177/0146645318764091

8. Nelson GA, Simonsen LC, Huff JL. NASA evidence report: Risk of acute and late central nervous system effects from radiation exposure (2016). Available analyses of space-induced genetic and epigenetic changes, in strict correlation to phenotypic changes, during missions on the ISS and beyond [105]. The peculiar features of C. elegans, including the possibility of maintaining it in hibernation and growing within microfluidic devices, would make it ideally suited as an innovative bio-dosimeter for deep space missions, including those conducted through micro-satellite platforms. In summary, the resources, features, and knowledge offered by genetically tractable animal models, in particular C. elegans, make them excellent resources for studying the direct effects of cosmic radiation on neuron survival and function, in simulation experiments and, even more importantly, in real spaceflight missions.

\section{AUTHOR CONTRIBUTIONS}

FD conceived and wrote the manuscript. ED conceived and wrote the manuscript. GO surveyed literature and contributed to writing and editing. All authors contributed to the article and approved the submitted version.

\section{FUNDING}

The financial support to FD by Fondazione CRT is gratefully acknowledged. Research in the FD lab was also funded by the Associazione Italiana per la Ricerca sul Cancro (AIRC-grant IG 23341).

\section{ACKNOWLEDGMENTS}

The authors apologize for any unintentional omissions of references to previous work. online at: https://humanresearchroadmap.nasa.gov/Evidence/reports/CNS. pdf (accessed September 8, 2016).

9. Cucinotta FA, Cacao E. Risks of cognitive detriments after low dose heavy ion proton exposures. Int J Radiat Biol. (2019) 95:985-98. doi: 10.1080/09553002.2019.1623427

10. Kiffer F, Boerma M, Allen A. Behavioral effects of space radiation: A comprehensive review of animal studies. Life Sci Space Res. (2019) 21:1-21. doi: 10.1016/j.lssr.2019.02.004

11. Carr H, Alexander TC, Groves T, Kiffer F, Wang J, Price E, et al. Early effects of $16 \mathrm{O}$ radiation on neuronal morphology and cognition in a murine model. Life Sci Space Res. (2018) 17:63-73. doi: 10.1016/j.lssr.2018. 03.001

12. Cekanaviciute E, Rosi S, Costes SV. Central nervous system responses to simulated galactic cosmic rays. Int J Mol Sci. (2018) 19:1-14. doi: 10.3390/ijms 19113669

13. Townsend LW, Chairman, Badhwar GD, Braby LA, Blakely EA, Cucinotta FA, et al. Report No. 153 - Information Needed to Make Radiation Protection Recommendations for Space Missions Beyond Low-Earth Orbit (2006). NCRP Bethesda, MD. Available Online at: https://ncrponline.org/ shop/reports/report-no-153-information-needed-to-make-radiationprotection-recommendations-for-space-missions-beyond-low-earthorbit-2006/

14. Carnell L. "Evidence Report: Risk of Acute Radiation Syndromes Due to Solar Particle Events" (2016), (available at https://ntrs.nasa.gov/search.jsp? $\mathrm{R}=20160003870$ ). 
15. Badhwar GD, O’Neill PM. Long-term modulation of galactic cosmic radiation and its model for space exploration. Adv Space Res. (1994) 14:74957. doi: 10.1016/0273-1177(94)90537-1

16. Tucker JD, Marples B, Ramsey MJ, Lutze-Mann LH. Persistence of chromosome aberrations in mice acutely exposed to $56 \mathrm{Fe}+26$ ions. Radiat Res. (2004) 161:648-55. doi: 10.1667/RR3177

17. Slaba TC, Bahadori AA, Reddell BD, Singleterry RC, Clowdsley MS, Blattnig SR. Optimal shielding thickness for galactic cosmic ray environments. Life Sci Space Res. (2017) 12:1-15. doi: 10.1016/j.lssr.2016. 12.003

18. Mishra B, Lawson GW, Ripperdan R, Ortiz L, Luderer U. Charged-ironparticles found in galactic cosmic rays are potent inducers of epithelial ovarian tumors. Radiat Res. (2018) 190:142-50. doi: 10.1667/RR15028.1

19. Maalouf M, Durante M, Foray N. Biological effects of space radiation on human cells: history, advances outcomes. J Radiat Res. (2011) 52:126-46. doi: 10.1269/jrr.10128

20. Elmore E, Lao X-Y, Kapadia R, Swete M, Redpath JL. Neoplastic transformation in vitro by mixed beams of high-energy iron ions and protons. Radiat Res. (2011) 176:291-302. doi: 10.1667/RR2646.1

21. Norbury JW, Schimmerling W, Slaba TC, Azzam EI, Badavi FF, Baiocco $\mathrm{G}$, et al. Galactic cosmic ray simulation at the NASA Space Radiation Laboratory. Life Sci Space Res. (2016) 8:38-51. doi: 10.1016/j.lssr.2016.02.001

22. Slaba TC, Blattnig SR, Norbury JW, Rusek A, Tessa CL, Walker SA. GCR Simulator Reference Field and a Spectral Approach for Laboratory Simulation, NASA Technical Publication. Langley, VA: NASA (2015).

23. Cucinotta FA, M.-Kim HY, Willingham V, George KA. Physical and biological organ dosimetry analysis for international space station astronauts. Radiat Res. (2008) 170:127-38. doi: 10.1667/RR1330.1

24. Parihar VK, Allen B, Tran KK, Macaraeg TG, Chu EM, Kwok SF, et al. What happens to your brain on the way to Mars. Sci Adv. (2015) 1:e1400256. doi: $10.1126 /$ sciadv.1400256

25. Parsons JL, Townsend LW. Interplanetary crew dose rates for the August 1972 solar particle event. Radiat Res. (2000) 153:729-33. doi: 10.1667/00337587(2000)153[0729:ICDRFT]2.0.CO;2

26. M.-Kim HY, Cucinotta FA, Wilson JW. A temporal forecast of radiation environments for future space exploration missions. Radiat Environ Biophys. (2007) 46:95-100. doi: 10.1007/s00411-006-0080-1

27. Strangman GE, Sipes W, Beven G. Human cognitive performance in spaceflight and analogue environments. Aviat Space Environ Med. (2014) 85:1033-48. doi: 10.3357/ASEM.3961.2014

28. Bromet EJ, Havenaar JM, Guey LT. A 25 year retrospective review of the psychological consequences of the Chernobyl accident. Clin Oncol. (2011) 23:297-305. doi: 10.1016/j.clon.2011.01.501

29. Yamada M, Kasagi F, Mimori Y, Miyachi T, Ohshita T, Sasaki H, et al. Incidence of dementia among atomic-bomb survivors-Radiation Effects Research Foundation Adult Health Study. J Neurol Sci. (2009) 281:11-4. doi: 10.1016/j.jns.2009.03.003

30. Greene-Schloesser D, Robbins ME. Radiation-induced cognitive impairment-from bench to bedside. Neuro-oncology. (2012) 14(Suppl. 4):iv37-44. doi: 10.1093/neuonc/nos196

31. Greene-Schloesser D, Robbins ME, Peiffer AM, Shaw EG, Wheeler KT, Chan MD. Radiation-induced brain injury: a review. Front Oncol. (2012) 2:73. doi: 10.3389/fonc.2012.00073

32. Mohamed Ali, Mathis T, Bensadoun R-J, Thariat J. Radiation induced optic neuropathy: Does treatment modality influence the risk? Bull Cancer. (2019) 106:1160-76. doi: 10.1016/j.bulcan.2019.09.008

33. Tabrizi S, Yeap BY, Sherman JC, Nachtigall LB, Colvin MK, Dworkin M, et al. Long-term outcomes and late adverse effects of a prospective study on proton radiotherapy for patients with low-grade glioma. Radiother Oncol. (2019) 137:95-101. doi: 10.1016/j.radonc.2019.04.027

34. Lesueur P, Calugaru V, Nauraye C, Stefan D, Cao K, Emery E, et al. Proton therapy for treatment of intracranial benign tumors in adults: a systematic review. Cancer Treat Rev. (2019) 72:56-64. doi: 10.1016/j.ctrv.2018.11.004

35. Fabrikant JI, Levy RP, Steinberg GK, Phillips MH, Frankel KA, Lyman JT, et al. Charged-particle radiosurgery for intracranial vascular malformations. Neurosurg Clin N Am. (1992) 3:99-139. doi: 10.1016/S1042-3680(18)30685-5

36. Steinberg GK, Fabrikant JI, Marks MP, Levy RP, Frankel KA, Phillips $\mathrm{MH}$, et al. Stereotactic helium ion Bragg peak radiosurgery for intracranial arteriovenous malformations. Detailed clinical and neuroradiologic outcome. Stereotact Funct Neurosurg. (1991) 57:36-49. doi: 10.1159/000099554

37. Lev MH. The long-term effects of spaceflight on human brain physiology. Radiology. (2020) 295:649-50. doi: 10.1148/radiol.20202 01164

38. Sinclair WK. Radiation protection issues in galactic cosmic ray risk assessment. Adv Space Res. (1994) 14:879-84. doi: 10.1016/0273-1177(94)90553-3

39. Taylor HL, Smith JC, Hatfield CA. Immediate Behavioral Detection of X-Rays by the Rhesus Monkey" (Florida State Univ Tallahassee, 1967). Available online at https://apps.dtic.mil/seo/citations/AD0660580

40. Brown W, McDowell A, Haley T, Snider R. Human Research Program Space Radiation Program Element. Response of the Nervous System to Ionizing Radiation. New York,NY: Academic Press, (1962). p. 729-46.

41. Melville GS, Brown WL, McDowell AA, Pickering JE, Harrison GW, Leffingwell TP, et al. Some effects of mixed ionizing radiations on Rhesus primates exposed under laboratory conditions. SAM-TR-66-48. Tech Rep SAM-TR. (1966) 1-27.

42. Britten RA, Davis LK, Johnson AM, Keeney S, Siegel A, Sanford LD, et al. Low (20 cGy) doses of $1 \mathrm{GeV} / \mathrm{u}$ (56)Fe-particle radiation lead to a persistent reduction in the spatial learning ability of rats. Radiat Res. (2012) 177:14651. doi: 10.1667/RR2637.1

43. Wyrobek AJ, Britten RA. Individual variations in dose response for spatial memory learning among outbred wistar rats exposed from 5 to $20 \mathrm{cGy}$ of (56) Fe particles. Environ Mol Mutagen. (2016) 57:331-40. doi: 10.1002/em. 22018

44. Lonart G, Parris B, Johnson AM, Miles S, Sanford LD, Singletary SJ, et al. Executive function in rats is impaired by low (20 cGy) doses of $1 \mathrm{GeV} / \mathrm{u}$ (56)Fe particles. Radiat Res. (2012) 178:289-94 doi: 10.1667/ RR2862.1

45. Rabin BM, Hunt WA, Joseph JA. An assessment of the behavioral toxicity of high-energy iron particles compared to other qualities of radiation. Radiat Res. (1989) 119:113-22. doi: 10.2307/3577371

46. Son Y, Yang M, Kim JS, Kim J, Kim SH, Kim JC, et al. Hippocampal dysfunction during the chronic phase following a single exposure to cranial irradiation. Exp Neurol. (2014) 254:134-44. doi: 10.1016/j.expneurol.2014.01.018

47. Parihar VK, Allen BD, Caressi C, Kwok S, Chu E, Tran KK, et al. Cosmic radiation exposure and persistent cognitive dysfunction. Sci Rep. (2016) 6:34774. doi: 10.1038/srep34774

48. Krukowski K, Grue K, Frias ES, Pietrykowski J, Jones T, Nelson $\mathrm{G}$, et al. Female mice are protected from space radiation-induced maladaptive responses. Brain Behav Immun. (2018) 74:106-20. doi: 10.1016/j.bbi.2018.08.008

49. Madabhushi R, Pan L, Tsai L-H. DNA damage and its links to neurodegeneration. Neuron. (2014) 83:266-82. doi: 10.1016/j.neuron.2014.06.034

50. Yamamoto ML, Hafer K, Reliene R, Fleming S, Kelly O, Hacke K, et al. Effects of $1 \mathrm{GeV} /$ nucleon (56)Fe particles on longevity, carcinogenesis and neuromotor ability in atm-deficient mice. Radiat Res. (2010) 175:231-9. doi: $10.1667 / R R 2312.1$

51. Worgul BV, Smilenov L, Brenner DJ, Vazquez M, Hall EJ. Mice heterozygous for the ATM gene are more sensitive to both X-ray and heavy ion exposure than are wildtypes. Adv Space Res. (2005) 35:254-9. doi: 10.1016/j.asr.2005.01.030

52. Vlkolinsky R, Titova E, Krucker T, Chi BB, Staufenbiel M, Nelson GA, et al. Exposure to 56Fe-particle radiation accelerates electrophysiological alterations in the hippocampus of APP23 transgenic mice. Radiat Res. (2010) 173:342-52. doi: 10.1667/RR1825.1

53. Yeiser LA, Villasana LE, Raber J. ApoE isoform modulates effects of cranial ${ }^{56} \mathrm{Fe}$ irradiation on spatial learning and memory in the water maze. Behav Brain Res. (2013) 237:207-14. doi: 10.1016/j.bbr.2012. 09.029

54. Rudobeck E, Bellone JA, Szücs A, Bonnick K, Mehrotra-Carter S, Badaut $\mathrm{J}$, et al. Low-dose proton radiation effects in a transgenic mouse model of Alzheimer's disease - Implications for space travel. PLoS ONE. (2017) 12:e186168. doi: 10.1371/journal.pone.0186168 
55. Gilbert R, Torres M, Clemens R, Hateley S, Hosamani R, Wade W, et al. Spaceflight and simulated microgravity conditions increase virulence of Serratia marcescens in the Drosophila melanogaster infection model. NPJ Microgravity. (2020) 6:4. doi: 10.1038/s41526-019-0091-2

56. Ma L, Ma J, Xu K. Effect of spaceflight on the circadian rhythm, lifespan and gene expression of Drosophila melanogaster. PLoS ONE. (2015) 10:e0121600. doi: 10.1371/journal.pone.0121600

57. Kim CS, Seong KM, Lee BS, Lee IK, Yang KH, Kim J-Y, et al. Chronic lowdose $\gamma$-irradiation of Drosophila melanogaster larvae induces gene expression changes and enhances locomotive behavior. J Radiat Res. (2015) 56:475-84. doi: $10.1093 / \mathrm{jrr} / \mathrm{rru} 128$

58. Hartman PS, Hlavacek A, Wilde H, Lewicki D, Schubert W, Kern $\mathrm{RG}$, et al. A comparison of mutations induced by accelerated iron particles versus those induced by low earth orbit space radiation in the FEM-3 gene of Caenorhabditis elegans. Mutat Res. (2001) 474:47-55. doi: 10.1016/S0027-5107(00)00154-8

59. Gao Y, Xu D, Zhao L, Sun Y. The DNA damage response of C. elegans affected by gravity sensing and radiosensitivity during the Shenzhou- 8 spaceflight. Mutat. Res. (2017) 795:15-26. doi: 10.1016/j.mrfmmm.2017.01.001

60. Honda Y, Higashibata A, Matsunaga Y, Yonezawa Y, Kawano T, Higashitani $A$, et al. Genes down-regulated in spaceflight are involved in the control of longevity in Caenorhabditis elegans. Sci Rep. (2012) 2:487. doi: $10.1038 /$ srep00487

61. Sakashita T, Takanami T, Yanase S, Hamada N, Suzuki M, Kimura T, et al. Radiation biology of caenorhabditis elegans: germ cell response, aging and behavior. J Radiat Res. (2010) 51:107-21. doi: 10.1269/jrr.09100

62. Maremonti E, Eide DM, Oughton DH, Salbu B, Grammes F, Kassaye YA, et al. Gamma radiation induces life stage-dependent reprotoxicity in Caenorhabditis elegans via impairment of spermatogenesis. Sci Total Environ. (2019) 695:133835. doi: 10.1016/j.scitotenv.2019.133835

63. Sakashita T, Hamada N, Ikeda DD, Suzuki M, Yanase S, Ishii N, et al. Locomotion-learning behavior relationship in Caenorhabditis elegans following gamma-ray irradiation. J Radiat Res. (2008) 49:285-91. doi: $10.1269 /$ jrr.07102

64. Sakashita T, Hamada N, Ikeda DD, Yanase S, Suzuki M, Ishii N, et al. Modulatory effect of ionizing radiation on food- $\mathrm{NaCl}$ associative learning: the role of gamma subunit of $\mathrm{G}$ protein in Caenorhabditis elegans. FASEB. (2008) 22:713-20. doi: 10.1096/fj.07-9259com

65. Britten RA, Jewell JS, Duncan VD, Davis LK, Hadley MM, Wyrobek AJ. Spatial memory performance of socially mature wistar rats is impaired after exposure to low (5 cGy) doses of $1 \mathrm{GeV} / \mathrm{n} 48 \mathrm{Ti}$ particles. Radiat Res. (2017) 187:60-5. doi: 10.1667/RR14550.1

66. Yang L, Yang J, Li G, Li Y, Wu R, Cheng J, et al. Pathophysiological responses in rat and mouse models of radiation-induced brain injury. Mol Neurobiol. (2017) 54:1022-32. doi: 10.1007/s12035-015-9628-x

67. Krukowski K, Feng X, Paladini MS, Chou A, Sacramento K, Grue K, et al. Temporary microglia-depletion after cosmic radiation modifies phagocytic activity and prevents cognitive deficits. Sci Rep. (2018) 8:7857. doi: 10.1038/s41598-018-28390-1

68. Rosi S. The final frontier: Transient microglia reduction after cosmic radiation exposure mitigates cognitive impairments and modulates phagocytic activity. Brain Circ. (2018) 4:109-13. doi: 10.4103/bc.bc_ $24 \_18$

69. Tseng BP, Giedzinski E, Izadi A, Suarez T, Lan ML, Tran KK, et al. Functional consequences of radiation-induced oxidative stress in cultured neural stem cells and the brain exposed to charged particle irradiation. Antioxid Redox Signal. (2014) 20:1410-22. doi: 10.1089/ars.2012. 5134

70. Overbey EG, Paul AM, da Silveira WA, Tahimic CGT, Reinsch SS, Szewczyk $\mathrm{N}$, et al. Mice exposed to combined chronic low-dose irradiation and modeled microgravity develop long-term neurological sequelae. Int J Mol Sci. (2019) 20:4094. doi: 10.3390/ijms20174094

71. Hall EJ, Brenner DJ, Worgul B, Smilenov L. Genetic susceptibility to radiation. Adv Space Res. (2005) 35:249-53. doi: 10.1016/j.asr.2004.12.032

72. Mavrou A, Tsangaris GT, Roma E, Kolialexi A. The ATM gene and ataxia telangiectasia. Anticancer Res. (2008) 28:401-5.
73. Swift M, Reitnauer PJ, Morrell D, Chase CL. Breast other cancers in families with ataxia-telangiectasia. N Engl J Med. (1987) 316:1289-94. doi: 10.1056/NEJM198705213162101

74. Hall EJ, Schiff PB, Hanks GE, Brenner DJ, Russo J, Chen J, et al. A preliminary report: frequency of A-T heterozygotes among prostate cancer patients with severe late responses to radiation therapy. Cancer J Sci Am. (1998) 4:385-9.

75. Peng Y, Nagasawa H, Warner C, Bedford JS. Genetic susceptibility: radiation effects relevant to space travel. Health Phys. (2012) 103:607-20. doi: 10.1097/HP.0b013e31826945b9

76. Lindsay KJ, Coates PJ, Lorimore SA, Wright EG. The genetic basis of tissue responses to ionizing radiation. Br J Radiol. (2007) 80:S2-6. doi: 10.1259/bjr/60507340

77. Gatti RA. The inherited basis of human radiosensitivity. Acta Oncol. (2001) 40:702-11. doi: 10.1080/02841860152619115

78. Neubauer S, Arutyunyan R, Stumm M, Dörk T, Bendix R, Bremer M, et al. Radiosensitivity of ataxia telangiectasia and Nijmegen breakage syndrome homozygotes and heterozygotes as determined by three-color FISH chromosome painting. Radiat Res. (2002) 157:312-21. doi: 10.1667/ 0033-7587(2002)157[0312:ROATAN]2.0.CO;2

79. Jacobsen E, Beach T, Shen Y, Li R, Chang Y. Deficiency of the Mre11 DNA repair complex in Alzheimer's disease brains. Brain Res Mol Brain Res. (2004) 128:1-7. doi: 10.1016/j.molbrainres.2004.05.023

80. Shackelford DA. DNA end joining activity is reduced in Alzheimer's disease. Neurobiol. Aging. (2006) 27:596-605. doi: 10.1016/j.neurobiolaging.2005.03.009

81. Bender A, Krishnan KJ, Morris CM, Taylor GA, Reeve AK, Perry RH, et al. High levels of mitochondrial DNA deletions in substantia nigra neurons in aging and Parkinson disease. Nat Genet. (2006) 38:515-7. doi: $10.1038 /$ ng 1769

82. Kraytsberg Y, Kudryavtseva E, McKee AC, Geula C, Kowall NW, Khrapko K. Mitochondrial DNA deletions are abundant and cause functional impairment in aged human substantia nigra neurons. Nat Genet. (2006) 38:518-20. doi: 10.1038/ng1778

83. Burla R, La Torre M, Zanetti G, Bastianelli A, Merigliano C, Del Giudice S, et al. Saggio, p53-Sensitive Epileptic Behavior and Inflammation in Ft1 Hypomorphic Mice. Front Genet. (2018) 9:581. doi: 10.3389/fgene.2018.00581

84. Kim D, Frank CL, Dobbin MM, Tsunemoto RK, Tu W, Peng PL, et al. Deregulation of HDAC1 by p25/Cdk5 in neurotoxicity. Neuron. (2008) 60:803-17. doi: 10.1016/j.neuron.2008.10.015

85. Liu B, Hinshaw RG, Le KX, Park M-A, Wang S, Belanger AP, et al. Space-like 56Fe irradiation manifests mild, early sex-specific behavioral and neuropathological changes in wildtype and Alzheimer's-like transgenic mice. Sci Rep. (2019) 9:12118. doi: 10.1038/s41598-019-48615-1

86. Mirzayans R, Andrais B, Scott A, Wang YW, Murray D. Ionizing radiationinduced responses in human cells with differing TP53 status. Int J Mol Sci. (2013) 14:22409-35. doi: 10.3390/ijms141122409

87. Wnorowski A, Sharma A, Chen H, Wu H, Shao N-Y, Sayed N, et al. Effects of Spaceflight on Human Induced Pluripotent Stem Cell-Derived Cardiomyocyte Structure and Function. Stem Cell Reports. (2019) 13:960-9. doi: 10.1016/j.stemcr.2019.10.006

88. Maruyama K, Iwanami N, Maruyama-Hayakawa T, Doi K, Wang B. A small fish model for quantitative analysis of radiation effects using visualized thymus responses in GFP transgenic medaka. Int J Radiat Biol. (2019) 95:1144-9. doi: 10.1080/09553002.2019.1589019

89. Yasuda T, Kamahori M, Nagata K, Watanabe-Asaka T, Suzuki M, Funayama $\mathrm{T}$, et al. Abscopal activation of microglia in embryonic fish brain following targeted irradiation with heavy-ion microbeam. Int J Mol Sci. (2017) 18:1428. doi: $10.3390 /$ ijms 18071428

90. Di Schiavi E, Andrenacci D. Invertebrate models of kallmann syndrome: molecular pathogenesis and new disease genes. Curr Genomics. (2013) 14:210. doi: 10.2174/138920213804999174

91. Martinelli S, Cordeddu V, Galosi S, Lanzo A, Palma E, Pannone L, et al. Co-occurring WARS2 and CHRNA6 mutations in a child with a severe form of infantile parkinsonism. Parkinsonism Relat Disord. (2020) 72:75-9. doi: 10.1016/j.parkreldis.2020.02.003 
92. Rizzo F, Nizzardo M, Vashisht S, Molteni E, Melzi V, Taiana M, et al. Key role of SMN/SYNCRIP and RNA-Motif 7 in spinal muscular atrophy: RNASeq and motif analysis of human motor neurons. Brain. (2019) 142:276-94. doi: 10.1093/brain/awy330

93. Gallotta I, Mazzarella N, Donato A, Esposito A, Chaplin JC, Castro S, et al. Neuron-specific knock-down of SMN1 causes neuron degeneration and death through an apoptotic mechanism. Hum Mol Genet. (2016) 25:2564-77. doi: $10.1093 / \mathrm{hmg} / \mathrm{ddw} 119$

94. de Carlos Cáceres, Porto DA, Gallotta I, Santonicola P, Rodríguez-Cordero J, Di Schiavi E, et al. elegans neurodegeneration mutants enabled by microfluidics and image analysis algorithms. Integr Biol. (2018) 10:539-48. doi: 10.1039/C8IB00091C

95. Ishioka N, Higashibata A. Space Experiments Using C. elegans as a Model Organism. Handbook of Space Pharmaceuticals. Pathak Y, M. Araújo dos Santos, Zea L, Eds. Cham: Springer International Publishing. (2019). p. 1-32

96. Nelson GA, Schubert WW, Kazarians GA. Richards GF, development and chromosome mechanics in nematodes: results from IML-1. Adv Space Res. (1994) 14:209-14. doi: 10.1016/0273-1177(94)90405-7

97. Szewczyk NJ, Tillman J, Conley CA, Granger L, Segalat L, Higashitani $\mathrm{A}$, et al. Description of International Caenorhabditis elegans Experiment first flight (ICE-FIRST). Adv Space Res. (2008) 42:1072-9. doi: 10.1016/j.asr.2008.03.017

98. Brenner S. The genetics of Caenorhabditis elegans. Genetics. (1974) 77:7194.

99. Ankeny RA. The natural history of Caenorhabditis elegans research. Nat Rev Genet. (2001) 2:474-9. doi: 10.1038/35076538

100. Xu Y, Chen L, Liu M, Lu Y, Yue Y, Liu Y, et al. High-throughput transcriptome sequencing reveals extremely high doses of ionizing radiation-response genes in Caenorhabditis elegans. Toxicol Res. (2019) 8:754-66. doi: 10.1039/c9tx00101h

101. Hartman PS. Epistatic interactions of radiation-sensitive (rad) mutants of Caenorhabditis elegans. Genetics. (1985) 109:81-93.

102. Weidhaas JB, Eisenmann DM, Holub JM, Nallur SV. A Caenorhabditis elegans tissue model of radiation-induced reproductive cell death. Proc Natl Acad Sci USA. (2006) 103:9946-51. doi: 10.1073/pnas.0603791103

103. Zhao Y, Johnsen R, Baillie D, Rose A. Worms in space? A model biological dosimeter. Gravit Space Biol Bull. (2005) 18:11-16.

104. Zhao Y, Lai K, Cheung I, Youds J, Tarailo M, Tarailo S, et al. A mutational analysis of Caenorhabditis elegans in space. Mutat Res. (2006) 601:19-29. doi: 10.1016/j.mrfmmm.2006.05.001

105. Montague TG, Almansoori A, Gleason EJ, Copeland DS, Foley K, Kraves S, et al. Gene expression studies using a miniaturized thermal cycler system on board the International Space Station. PLoS ONE. (2018) 13:e0205852. doi: 10.1371/journal.pone.0205852

Conflict of Interest: The authors declare that the research was conducted in the absence of any commercial or financial relationships that could be construed as a potential conflict of interest.

Copyright (c) 2020 Onorato, Di Schiavi and Di Cunto. This is an open-access article distributed under the terms of the Creative Commons Attribution License (CC BY). The use, distribution or reproduction in other forums is permitted, provided the original author(s) and the copyright owner(s) are credited and that the original publication in this journal is cited, in accordance with accepted academic practice. No use, distribution or reproduction is permitted which does not comply with these terms. 